\title{
Los niños y jóvenes en situación de calle como sujetos educativos
}

DOI: $\underline{\text { https://doi.org/10.32870/dse.v0i8.304 }}$

\section{Elvia Taracena Ruiz*}

Resumen: En este artículo se reflexiona sobre las posibilidades y los obstáculos para poder considerar a los niños y jóvenes de calle como sujetos educativos. El artículo comienza con una caracterización del lugar social que tiene esta población o a veces la falta de lugar y la falta de respuesta y de contención de las Instituciones Educativas. Se describen los principios curriculares y pedagógicos de un modelo educativo para jóvenes en riesgo de calle que se piloteó en Instituciones Gubernamentales y no gubernamentales, se presta particular atención a los obstáculos para la aplicación de este modelo. Obstáculos que provienen del mercado humanitario, del estigma que tienen esos jóvenes, de la dificultad de considerarlos sujetos educativos y de la falta de apoyo para programas de desintoxicación y de ayuda. Palabras clave: jóvenes en riesgo de calle, memoria social, modelo educativo.

\begin{abstract}
This paper reflects on the possibilities and obstacles to consider the children and youth in street situation as subjects of education. It begins with a characterization of the social place that this population has, or even the lack of place, as well as the absence of a proper response or containment form the Educational Institutions. The curricular and pedagogical principles of a youth-in-risk-of-street-situation educational model are described. This model was piloted on governmental organizations. One of the main focus are the obstacles to the application of this model, in particular the ones that come from the humanitarian market, the social stigma that these youngsters have, the difficulty to consider them as subjects of education, and the lack of support for the detoxifications and aid programs. Key Words: youth in risk of street situation, social memory, educational model.
\end{abstract}

\section{Introducción}

Hablar de los jóvenes en situación de calle como sujetos educativos implica pensar en un joven que es capaz de manifestar deseos y que está inscrito en un proyecto social en donde acepta las normas de la sociedad. Sin embargo, todos los jóvenes con los que hemos trabajado han tenido una historia fallida con la escuela, no han encontrado un lugar en ella que implique el reconocimiento de sus capacidades.

Los jóvenes que sobreviven en las calles han sido excluidos de las instituciones, la familia, la escuela, los centros de salud y les queda la calle para inventar formas diferentes de vivir con sus propias reglas y sus formas de relación. Es un modo de vida en donde privilegian el aquí y el ahora en sus relaciones y en sus actividades.

Este artículo está construido en tres secciones: en la primera se presenta una reflexión sobre la memoria y la identidad, lo que nos parece un núcleo central de la construcción psíquica del joven

*Profesora e Investigadora. FES Iztacala-UNAM. Correo electrónico: etaracenar@yahoo.com. Tel. 5623-1170. 
en situación de calle y que es el resultado de la mirada social que se tiene de ellos. En la segunda presentaremos el enfoque teórico metodológico utilizado en nuestro trabajo, no sólo para lo que se presenta en este artículo, sino globalmente para la investigación-intervención que hemos realizado con ésta población. En la tercera sección abordaremos una experiencia, concreta de propuesta y piloteo, de un modelo educativo creado tomando en cuenta las características y los saberes de estos jóvenes e intentando contrarrestar las acciones de estigmatización que se realizan cotidianamente hacia ellos.

Nos parece que la reflexión que precede a la presentación del piloteo del modelo educativo y de los obstáculos que encontramos, permitirá al lector comprender las razones de estas dificultades, además de constituir un núcleo importante en la aplicación del modelo, en donde se trata de ofrecer alternativas de construcción de sí mismo y de ocupar otro lugar en la sociedad.

\section{Enfoque teórico metodológico}

En los últimos veinte años hemos trabajado el tema de la desigualdad social, desde el punto de vista teórico, como en el de investigación e intervención.

No vemos como dos procesos separados el de la investigación y el de la intervención. En los diversos acercamientos realizados, hemos ido reuniendo datos que nos permiten reflexionar sobre el fenómeno de la vida en la calle. En cada una de las investigaciones-intervenciones hemos privilegiado la relación con los jóvenes, el tomar en cuenta sus necesidades y el restituirles algo en intercambio de su aceptación de compartirnos sus vivencias. En general hemos realizado actividades lúdicas y educativas con los callejeros en sus espacios de vida. Hemos funcionado también como intermediarios con las instituciones para negociar un trato más justo, intentando hacer valer su lugar como ciudadanos, a la par que dialogamos, observamos y entrevistamos a los muchachos (Taracena y Tavera, 2000).

En una concepción clínica de la investigación en psicología social, éste trabajo está íntimamente ligado a una intervención práctica. En esta concepción el investigador trabaja en la implicación, tomando en cuenta esta característica como una parte central del proceso de investigación. Inserto en esta visión nuestro trabajo práctico, en los últimos años, se dirige a participar en un proceso donde dichos grupos puedan negociar un lugar en la sociedad, más allá de la simple exclusión, donde la sociedad sea capaz de crear espacios de escucha, y pueda re-significar su presencia. La investigación permite crear un cuadro conceptual con fines de comprensión y heurísticos. La intervención permite insertarse en un movimiento social que implica una toma de posición ideológica y de acción.

Hemos elegido trabajar teóricamente con un enfoque multireferencial, en donde vamos construyendo un andamiaje teórico que toma en cuenta la construcción del objeto de estudio, en este caso la vida en la calle como creación de nuevas subjetividades (Taracena, 2010). En este caso, la reflexión de la memoria social desde la historia y de la sociología, se integra a una reflexión sobre 
la identidad que retoma autores de la psicología, las ciencias de la educación y la sociología. Para la parte del análisis del piloteo y de las características del educador nos ayudamos de autores del psicoanálisis.

\section{La memoria social y la identidad estigmatizada}

La necesidad de los niños y jóvenes de tomar las calles nos permite plantearnos algunas preguntas de interés central para las ciencias sociales, algunas de ellas son: ¿Cómo interioriza el individuo la imagen que los demás le proyectan de él mismo? y ¿cómo puede construirse el individuo tomando en cuenta ésta imagen?, ¿qué memoria elige la sociedad de los grupos excluidos y cuáles son los olvidos?

Quisiéramos relacionar estas dos preguntas con la reflexión que han hecho una serie de autores alrededor de la construcción de la identidad de la persona y de la transmisión de la memoria.

Camilleri et al. (1990) consideran que para explicar la identidad hay que tomar en cuenta, primero, los procesos de identificación y de apego afectivo; el acento debe ponerse en la percepción que tiene de sí mismo el sujeto y se debe tomar en consideración el peso del inconsciente sobre sus deseos y sus elecciones.

Lipiansky (1992) afirma que la identidad se construye en un proceso dinámico en donde el individuo accede a la conciencia de sí mismo a de la diferenciación y asimilación con el otro. El otro le significa constantemente el lugar que tiene, su posición y su rol a través de sus grupos de pertenencia. Hay una interacción constante, nos dice el autor, entre los mecanismos de proyección y de introyección entre la identidad asumida por el yo y la que le es propuesta por el otro.

Los trabajos de Goffman (1973) por su cuenta reconocen la relatividad de las normas y el dinamismo de las identidades, basando su trabajo en las identidades estigmatizadas o negativas; pone el acento en la facultad que tiene el individuo como actor de verse, como si viera una película de su vida, actuando un papel (o una identidad); es decir señalando la distancia entre el "yo" y la identidad. Esta aproximación supone una cierta distancia entre las identidades del actor social y la esencia de su "yo", o si se quiere la existencia de dos clases de identidades, la identidad existencial y profunda que representa la continuidad de la persona y el conjunto de identidades que hace suyas a lo largo de su vida.

Algunos autores ponen el acento más en las estructuras y en la historia del sujeto, otros en las experiencias aquí-ahora, algunos más en la elaboración racional del individuo de su identidad, otros en los procesos inconscientes, algunos más en el grupo, otros en el individuo; pero lo que es innegable es que todos coinciden en que la imagen que los otros proyectan al individuo sobre sí mismo, es fundante para su identidad.

Este rápido recorrido sobre autores que han trabajado con el concepto de identidad, me permite plantear dos aspectos importantes: el primero es que la percepción que el sujeto tiene de sí mismo conforma su sentimiento de identidad. El segundo consiste en que la existencia social está 
profundamente relacionada con la mirada del otro. Este otro puede ser una persona, un grupo o la sociedad en su conjunto, que a través de sus instituciones reconoce o no al sujeto y le devuelve ciertos aspectos de él.

Toda situación que produce angustia genera mecanismos de defensa para facilitar el afrontamiento, la sola presencia de los niños en las calles tiende a generar mecanismos de toma de distancia. La imposición de una imagen de posible delincuente, maleante o drogadicto que se impone al niño en situación de calle, genera una actitud de rechazo y de hostilidad hacia él, acentuando el proceso de por sí natural de toma de distancia y de exterioridad asociado a este fenómeno de nuestra sociedad.

Uno de los aspectos relacionados con la identidad y con la manera en que la sociedad da cuenta de un grupo de personas, de sus características y de su presencia es la cuestión de la memoria.

Sabemos que la sociedad tiene ciertos mecanismos de transmisión de la memoria, ya Halbwachs (2001) muestra en su libro Los marcos sociales de la memoria que las instituciones a través de las cuales se transmite ésta, son la familia, la religión, las instituciones, mientras que el Estado es quien escoge una memoria oficial.

Todorov (2000) reflexiona sobre los usos y abusos de la memoria en las diferentes civilizaciones y plantea que la historia se construye de acuerdo a los intereses de los grupos en el poder. A pesar de ello, no existe solamente la historia en mayúsculas: la historia forjada y manipulada por los Estados-Nación para dar un contenido a las identidades nacionales; existe también la historia cotidiana y la memoria colectiva de los pueblos. Es esta memoria quien se encarga de dar o de quitar un lugar a ciertos sectores de la sociedad. Pensamos que, la exclusión, en cierto sentido es una negación de la memoria de aquellos seres que la sociedad no acepta.

Hemos observado que la falta de lugar social, la falta de memoria de los marginados tiene un referente subjetivo. En el caso de los jóvenes de la calle, nuestro trabajo nos ha llevado a constatar este fenómeno. Frecuentemente se observa en ellos un rechazo a acordarse de su historia; hecho que resulta del todo comprensible, pues ésta es la única manera de subsistir en un mundo que ha sido lleno de rupturas, abandonos, violencia y pobreza; es olvidar y desde ese lugar construir un mundo propio, teniendo así la impresión de que son autosuficientes e independientes, construyendo además sus propias reglas, en oposición y en una situación de trasgresión de las normas existentes. Lo anterior da lugar a una manera de vivir día a día. Cuando los niños y jóvenes que sobreviven en las calles, reciben dinero, ropa, comida, etcétera, su actitud es, a menudo, gastar el dinero muy rápidamente y tirar la ropa cuando ya está sucia en lugar de lavarla y conservarla.

El grupo callejero se convierte en 'el espacio' para compartir experiencias con otros pares y sustituir la carencia de sus familias, en él la creación de sus propias reglas y la invención de sus propios sistemas de interrelación o convivencia personal, cobran un especial valor dentro de la conformación de su identidad. 
Sabemos que muchos de estos jóvenes no poseen o han extraviado sus papeles, y por ese hecho su identidad legal ha quedado confusa y vaga. Por otro lado a menudo ellos no quieren recordar su filiación, su historia familiar, de esta manera, ellos prefieran ser llamados con apodos o nombres ficticios; recurso que puede alimentar su fantasía de auto-creación y de sentimiento de auto-suficiencia.

En trabajos anteriores hemos analizado la función del grupo para los jóvenes en situación de calle, observándose que dichos grupos tienen como destino sustituir a la familia en su función de sostén y cada grupo tiene formas particulares de subsistencia, de creación de reglas y de selección de sus miembros (Taracena y Tavera, 2000).

Pensamos que el rechazo de guardar una memoria vinculada a sus orígenes, a su pertenencia familiar y/o a su historia personal, en los niños y jóvenes en situación de calle, tiene como equivalente la imposibilidad de que grupos intermedios como la familia, las instituciones o la sociedad en general, se manifiestan para incluir en la memoria a quienes como lugar se les ha asignado el lugar de lo negativo y la exclusión.

De hecho para muchos de los transeúntes, si bien esos niños existen sólo como posible peligro, son casi transparentes; muchos de ellos no podrían describirlos en sus rasgos personales aún cuando se encuentran con ellos todos los días en algunos cruceros de la ciudad.

Esta necesidad de hacer transparente su presencia, de negarlos y de hacerlos existir solamente como posible peligro, es consecuencia de la actitud de la sociedad de no asumir la responsabilidad ante este complejo problema.

Frecuentemente los programas gubernamentales tienen como objeto, casi único, hacer desaparecer a los niños de las calles; ya sea regresándolos a sus familias o internándolos en instituciones, sin plantearse realmente la posibilidad de re-socializarlos. Es así que se ha dejado esta tarea en manos de la sociedad civil a través de asociaciones y ONG que se ocupan de estos jóvenes y es, precisamente, la sociedad civil quien ha respondido haciéndose cargo de dignificar la vida de estos jóvenes. Hay una gran diversidad de maneras de hacerse cargo de estos jóvenes en las ONG, desde las propuestas de orden religioso que intentan a través del amor 'exigente' rescatar al niño de la calle, hasta las que ponen en el centro del problema la ciudadanía y los derechos de los niños. Las organizaciones civiles han retomado los resultados de sus experiencias para mejorar las propuestas de trabajo con los niños en situación de calle, y cada vez hay más redes y más vínculos entre las mismas y los grupos de investigadores en las Universidades para mejorar los sistemas y las prácticas de intervención.

La relación entre memoria individual y memoria social nos permite pensar la identidad del individuo desde otra perspectiva. En lo individual podemos hablar de un sentimiento de identidad que está íntimamente relacionado con la identidad social. Retomando a Rosset (1999) consideramos que nuestra personalidad social es una creación del pensamiento de los otros y desde el punto de vista del yo, esta personalidad en el terreno individual, nos permite asegurar una consistencia y continuidad de ese yo. 
Pienso que la intervención con jóvenes en situación de calle debe tomar en cuenta estos dos registros: el social y el individual planteando en su articulación modos de comprensión y de acompañamiento para proponer procesos de socialización que cobren sentido para ellos.

\section{La propuesta de un modelo educativo}

El trabajo con los grupos excluidos requiere una intervención que retome elementos del trabajo comunitario, de la educación y de la clínica. Se requiere un acompañamiento dirigido a facilitar la construcción de estrategias que permitan una reubicación social, respetando la cultura popular de donde proceden estas poblaciones. Requiere - en nuestra opinión - un trabajo preventivo, con dispositivos grupales, que favorezcan la reflexión y las posibilidades de elaboración como preámbulo a un trabajo individual.

Resulta importante pensar la educación de grupos con modos de socialización diferentes (niños trabajadores, niños migrantes, niños de origen indígena, niños en situación de calle) de manera alternativa a la de la escuela tradicional. Se necesita acercar la escuela a los niños y crear programas que se ajusten a sus recursos y condiciones de vida.

La primera tarea es —en nuestra opinión - el orientarlos y acompañarlos para regularizar su situación legal; esto les permitirá proyectarse socialmente de otra manera. Esta tarea se puede realizar en el contexto de una propuesta educativa flexible que les permita: adquirir conocimientos que sean relevantes en su vida cotidiana y relacionarse de una manera distinta con las reglas y con la autoridad.

Es necesario también un trabajo con los educadores de calle y con los profesionales que se han encargado de estos jóvenes con el objetivo de construir un diagnóstico colectivo de los problemas que atañen a estos grupos y de los problemas sociales que los han originado.

Nuestro equipo de trabajo consideró importante desarrollar un modelo pedagógico que permitiera a estos niños y jóvenes contemplar la posibilidad de incorporar un proyecto educativo como meta de desarrollo y que, subsecuentemente, éste impulse su re-articulación a la sociedad en condiciones de menor marginalidad. Hablar de educación para niños y jóvenes que se encuentran en proceso de salida a la calle significa reflexionar sobre cómo se debe adaptar este concepto a quienes han sido excluidos de la escuela formal y quienes han excluido, también, la estancia en la escuela como un proyecto viable para ellos.

En esta doble exclusión juegan procesos sociales y subjetivos que se entrecruzan, pues la escuela supone un niño con recursos materiales y sociales. En la población que se encuentra en situación de calle se multiplican los obstáculos que les impiden asistir a la escuela y satisfacer las demandas de la institución educativa. Deben, muchas veces, conseguir dinero para su subsistencia y la de sus familiares, por lo general carecen de la atención adecuada de sus padres, viven situaciones de violencia y, en la calle, son sujetos de discriminación y de estigmatización; algunos consumen drogas y no tienen acceso a programas de desintoxicación. 
La escuela tiene que transformar algunas de sus características, para dar cabida a los sujetos que han sido excluidos y que se han excluido de la sociedad; sin embargo, dado que el sistema escolar tiene en primer lugar una función normalizante, esta se convierte en el primer obstáculo para comprender la diferencia.

Con la idea de disminuir la distancia entre los grupos vulnerables y vulnerados y con la intención de articular la participación de diversos grupos de la sociedad civil, hemos desarrollado un modelo que, a) tomando en cuenta las experiencias de niños y jóvenes en situación de calle; b) considerando formas de atención educativa diferenciadas para las especificidades de cada población y c) utilizando los recursos de técnicas de innovación educativa; suscite un acercamiento diferente del niño y/o joven a la educación y promueva un mejoría física, mental y afectiva.

El desarrollo de este modelo en 2009 respondió a una invitación que se nos hizo y hemos diseñado, para la Subsecretaría de Educación Básica de la SEP, un modelo educativo para niños y jóvenes en situación de calle basado en las siguientes metas (Taracena y Albarrán, 2010):

- Recuperar propuestas pedagógicas ya producidos en la Secretaría de Educación Pública (SEP) como la Propuesta Educativa Multigrado y el Programa Migrantes SEP/DGDGIE para que, mediante una adecuación curricular enfocada a población en situación de calle, se impulse su nivelación escolar y estos grupos puedan cursar los estudios de primaria y obtener una acreditación oficial.

- Favorecer la obtención de sus documentos de identidad y trabajar para que conozcan sus derechos y obligaciones como ciudadanos.

- Trabajar mediante 'autobuses-escuela' con distintas unidades pedagógicas de tipo lúdicoartísticas para el desarrollo del contenido curricular adaptado.

- Capacitarlos en talleres productivos que les brindarán herramientas para desarrollar actividades generadoras de ingresos económicos.

- Pilotear 'Escuelas-Taller' en donde el niño o el joven pudiera permanecer gran parte del día: estudiando y también aprendiendo y realizando alguna actividad generadora de recursos económicos.

- Acercarlos al arte y facilitar el conocimiento de diversas expresiones creativas.

- Desarrollar un trabajo multidisciplinario que promueva la desintoxicación y disminución de prácticas de riesgo.

- Impulsar un trabajo personal que favoreciera la elaboración de su historia de vida, la recreación de su historia y la construcción de un proyecto a futuro distinto de la callejerización. 
Algunos de los ejes que tomamos en cuenta para la elaboración de este modelo son los siguientes:

Tomar en cuenta la experiencia del joven: las condiciones de supervivencia le han dejado aprendizajes

Aunque la socialización de los jóvenes de la calle es muy diferente de la de los niños que tienen un hogar y, a menudo, nos sorprende por la rudeza del mundo en el que viven, hay aspectos rescatables que deberían ser tomados en cuenta cuando se piensa en un modelo educativo dirigido a ellos.

Son poblaciones que le dan mucha importancia al presente, al momento; que tienen otra forma de percibir el tiempo y las relaciones con el otro. Tienen códigos diferentes para establecer sus reglas. Funcionan en la resistencia y tienen una inteligencia práctica.

Más que comparar sus formas de socialización con las de otros niños, para la estructuración de este modelo intentamos contemplar su forma particular de funcionamiento. El reto para nosotros fue producir un modelo que partiendo de la serie de códigos que ellos manejan, puedan llegar a establecer puentes con los códigos de otros grupos para así reducir su exclusión. Es decir, encontrar un lugar intermedio entre las reglas producidas por ellos y las reglas de la escuela.

\section{Proponer aprendizajes que sean significativos en su vida}

Aunque decidimos retomar los contenidos de la escuela primaria, se realizó un esfuerzo para que estos aprendizajes se tornaran significativos en su vida. Ya sea en el terreno de producir herramientas que les faciliten las condiciones de supervivencia, o produciendo saberes que estimulen su imaginación y les permita tener conciencia de su quehacer como ciudadanos y de su ser en el mundo (tal es el caso de los conocimientos de ciencias sociales), o bien, impulsando su formación técnica en actividades productivas generadoras de autoempleo que integren el desarrollo creativo y/o artístico en los jóvenes.

Crear una currícula con actividades pedagógicas vinculadas a su vida cotidiana así como en su realidad cultural y psicológica

Si bien los temas y los contenidos de nuestra propuesta curricular son semejantes a las de algunos programas desarrollados por la Secretaría de Educación Pública, como es el caso de la Propuesta Educativa Multigrado, se hizo un esfuerzo por incluir actividades que incorporen referentes contextuales de los niños y jóvenes en situación de calle; por ejemplo, utilizando los personajes con los que conviven más a menudo o aquellos que forman parte de su imaginario popular. Ha sido importante relacionar los conocimientos de tipo académico con saberes más cotidianos y con hechos que puedan resultar significativos en su historia de vida; tal es el caso de retomar personajes de la lucha libre o personas dedicadas a diversas actividades u oficios cercanos para estos jóvenes como el bolero, el mecánico, la comerciante, etcétera. 
Trabajar para que adquieran herramientas cognitivas, afectivas y metacognitivas en la resolución de problemas de la vida diaria

Una de las necesidades importantes para poder adquirir los conocimientos ofertados por el currículo de la escuela primaria, es el desarrollo de herramientas conceptuales y afectivas de las que a menudo carecen estos jóvenes o que se han visto circunscritas a la precariedad de la vida diaria, para ello se puso el énfasis en la resolución de los problemas específicos que enfrentan, por ejemplo cómo asistir a un hospital, cómo hacer un trámite para la obtención de documentos, cómo moverse por la ciudad. También se pensó en ofrecer un acompañamiento de los niños y jóvenes en la construcción de proyectos a corto y mediano plazo.

Proporcionarles medios de expresión como el arte para elaborar sus experiencias difíciles y favorecer la comunicación

El contacto con producciones artísticas y el hecho de favorecer actividades que le permita una expresión en ese terreno, representa para estos jóvenes una posibilidad de elaboración de experiencias traumáticas y de situaciones límite. Representa también darles una voz y una forma de reconocimiento, lo que favorece la comunicación y el lazo social.

Así, decidimos incluir actividades artísticas junto con los Talleres orientados a actividades productivas para alimentar su imaginario y proporcionarles formas alternativas de encontrar placer y remitirse a otra esfera de la realidad; búsqueda que ellos realizan a menudo en torno al consumo de las drogas.

\section{Acompañarlos para recuperar y/o revalorizar su historia}

Aunque las historias de los jóvenes de la calle son historias llenas de violencia, maltrato, carencias

y falta de reconocimiento; pensamos que deben contener también aspectos positivos que a menudo han sido olvidados entre la multitud de hechos y circunstancias difíciles por los que han transitado. El hecho de reconocer los aspectos más constructivos, los lazos positivos con otras personas, los momentos de reconocimiento o aceptación — por breves que hayan sido-, les puede permitir visualizar a estos jóvenes otra posibilidad de relación con su propia vida. Apostándole a esta posibilidad es que decidimos incluir en el currículo la posibilidad de un acompañamiento para la recuperación y re-invención de su historia personal.

\section{Brindarles modos de reconocimiento que les permita otra inserción social} Como ya se mencionaba al principio de este escrito, la exclusión tiene que ver con falta de reconocimiento y sabemos que ésta se presenta para los niños y jóvenes en situación de marginalización en todos los niveles: personal, familiar, institucional y social. Dicha reflexión nos ha guiado para subrayar la importancia de la figura del maestro, educador o monitor como parte central de una 
intervención educativa, pues será él quien deberá cumplir con la tarea de reconocer a ese joven en su diferencia, como persona, como educando, como ciudadano y permitirle mayor autonomía.

El educador deberá desarrollar la empatía necesaria para no repetir la falta de reconocimiento o solamente a través de características negativas, hasta ahora significada reiterativamente a estos jóvenes. Dicho objetivo depende de la posibilidad de construir modelos de identificación con personas que no sean violentas, que no abusen del poder y que, al mismo tiempo, puedan señalar los límites que fomenten una nueva relación con las reglas e impulse la resocialización de estos jóvenes; de esto dependerá — en gran medida — que el programa pueda construirse como posibilidad de un proyecto alternativo para estos jóvenes.

La relación maestro-alumno en el caso de alumnos vulnerables cobra mucha importancia. Si sabemos que el maestro representa una figura alternativa de identificación para los alumnos en lo que concierne a los valores, la actitud hacia el estudio, la filosofía de la vida, esto es mucho más importante en el caso de alumnos en situación de riego.

Por alumnos vulnerables queremos designar a aquellos cuyas condiciones familiares son precarias, que viven a menudo en ambientes de violencia y de carencias materiales, psicológicas y afectivas y que, frecuentemente, tienen dificultades para adherirse al sistema de escolarización.

Para estos chicos es esencial contar con figuras que representen una posibilidad de contención y de lazos afectivos, al mismo tiempo que un modelo diferente al que encuentran en su entorno; es decir, alguien no violento, comprensivo y dispuesto al diálogo.

Es importante analizar la implicación afectiva y personal del educador. No se trata de sustituir a la figura parental, pero sí de proporcionar al educando marcos de referencia desde la escuela para construir un modo diferente de vida y buscar formas de socialización en las que el alumno tenga una posición activa. Para la realización de esta tarea consideramos importante tener en cuenta los siguientes aspectos:

- Mostrar comprensión y al mismo tiempo rigor y firmeza.

- Propiciar un trabajo en equipo y de facilitar la ayuda entre pares.

- Adaptar los materiales educativos a las condiciones de los educandos.

- Necesidad de realizar un análisis de la contra-transferencia y de contar con un grupo de discusión y contención.

- La necesidad de recibir formación continua y un reconocimiento por la atención a grupos con necesidades especiales.

Un ejemplo del trabajo de análisis de la implicación de los educadores es el que se realizó en una casa de día dirigida a niños y jóvenes en situación de calle, en donde los participantes cobraron conciencia que en gran medida la elección de esa actividad se debía a que ellos mismos habían tenido infancias carenciadas y compartían con los niños que atendían situaciones de abandono y 
dificultades afectivas y económicas, esto les permitió comprender por qué en algunos casos llegaban hasta financiar de su propio salario las carencias de la institución y como se posicionaban ante estos chicos (Albarrán y Taracena, 2012).

En el trabajo de investigación realizado por Edith Flores, en Tepito, con un grupo de jóvenes que permanecen en las calles, con el fin de subsistir y de permanecer con un grupo de referencia, pudimos percatarnos que la presencia constante durante dos años que duró la investigación, la figura de la investigadora se convirtió en un adulto referente a la cual los jóvenes demandaban contención y ayuda para resolver sus problemas (Flores, 2010). Esta experiencia nos puso sobre la pista de la necesidad de crear una propuesta de atención que aunque no fuera con objetivos normalizadores, apuntara a la relación constante y fiable como modo de restablecimiento de los lazos sociales.

Winnicott (2005), psicoanalista inglés, dedicó buena parte de su vida a trabajar con adolescentes delincuentes y pudo constatar que los jóvenes pueden vivir con mucha ansiedad sus capacidades destructivas; es el adulto con su presencia estable y firme que puede ayudarle a sentir que sus impulsos destructivos son controlables. Para que esto sea posible se requiere mucha constancia y una presencia prolongada de un adulto fiable.

\section{Las unidades pedagógicas}

Una vez ubicados los contenidos temáticos que darían cuerpo al desarrollo curricular, se procedió a la tarea de realizar un diseño de cada una de las materias, mediante una metodología que comprendiera los objetivos y principios que ya se han mencionado, y se viera dotado de actividades lúdicas que involucraran la creatividad, el trabajo entre pares y la participación cooperativa.

Para su diseño se partió de la idea de que la formación se realizara a través de la colaboración activa entre educandos y el educador, para permitir la mejor comprensión de la vida social así como los contextos por los que transita el niño o joven. Dicho material integra un fichero en el que, también, se puede observar la materia a la que pertenece la actividad, el tema a trabajar, el objetivo por alcanzar y las habilidades a desarrollar.

A partir del piloteo en tres Instituciones se hicieron precisiones metodológicas en los contenidos, los elementos lúdico-creativos que favorecerían el aprendizaje e, incluso, las herramientas didácticas que se habían propuesto originalmente; en algunos casos se observó, por ejemplo, que la actividad requería conocimientos previos con los que no siempre se contaba y que era necesario incluir o reforzar previamente; o bien, el grado de complejidad no era acorde a la población que, a veces, requería mayores retos, inclusive, condiciones lúdicas distintas a las que se habían propuesto originalmente; así mismo, fue necesario considerar criterios relacionados con el grupo en específico donde se estaba aplicando el modelo: las costumbres, actividades o idiosincrasia de la organización en las que se desarrollaban los educandos; el número de participantes por grupo; el tiempo permitido en las instituciones para cada clase; los tiempos de trabajo de cada institución; 
los materiales con los que se contaba; la infraestructura existente y, de manera general, los recursos económicos y humanos que exigiría la aplicación ${ }^{1}$.

\section{Los talleres lúdico-productivos}

Con el interés de asociar la parte pedagógica con la formación en actividades encaminadas al autoempleo — cuya aplicabilidad permitiera mejorar las condiciones de vida a los educandos—, se desarrollaron talleres productivos que - aparte de formar habilidades técnicas en labores artesanales - también sirvieran como escenario para que los niños y jóvenes tuvieran acceso a todo el modelo educativo y la formación que éste entrañaba; ya fuera favoreciendo la regularización en áreas específicas en los niños que aún asistían a la escuela, impulsando la nivelación educativa en los que habían interrumpido su asistencia a la escuela pública, o permitiendo el aprendizaje en grupos multinivel o en grupos donde no se contara, incluso, con experiencia alguna dentro de la escuela.

Ante la heterogeneidad de posiciones en la ubicación del niño frente a los conocimientos de la escuela, se requirió hacer un diagnóstico individualizado del nivel educativo de los participantes para detectar cuáles eran los conocimientos previos con los que ya contaban. Dicho diagnóstico se desarrolló empleando como criterio las evaluaciones propuestas por el Instituto Nacional para la Educación de los Adultos (INEA) por cada materia y para cada nivel escolar.

Se puso énfasis en que los niños comprendieran todo el proceso de manufactura; desde aprender a estimar costos, la selección y compra de los materiales, así como la limpieza, presentación y venta de los productos.

Se consideró conveniente que el tema productivo fuera elegido por el grupo para dar importancia al interés y posibilidades de los educandos. Sin embargo, — retomando la información del diagnóstico sobre las necesidades educativas-, el educador tendría la responsabilidad de integrar en cada sesión las unidades pedagógicas necesarias; así como proponer la ruta pedagógica más adecuada para ese grupo en específico; es decir, podría comenzar por el objetivo que considerara idóneo de cualquier materia y tomar, subsecuentemente, los temas necesarios de esa misma o de cualquier otra materia en el orden que se necesitara, para dar sentido a la dinámica del taller. Las áreas que se trabajaron durante los talleres productivos fueron: Español, Matemáticas, Geografía, Ciencias Sociales y Ciencias Naturales. Estuvieron dirigidos a niños y niñas de entre 7 a 17 años de edad y se estructuraron en cada uno de los talleres de 11 a 23 sesiones dependiendo de las necesidades de la población, la institución y la disponibilidad de tiempo conforme lo establecido en los calendarios de las instituciones.

${ }^{1}$ Aquellos profesionales interesados en contar con una copia de las unidades pedagógicas propuestas en el modelo educativo, por favor escribir al correo: subjetividadysociedad@gmail.com o enviar un mensaje a la página Subjetividad y Sociedad de Facebook para hacerles llegar un DVD con el material. 
Los talleres lúdico-productivos se estructuraron en dos fases:

La primera fase estuvo relacionada con la parte educativa, para ello se recurrió a las unidades pedagógicas del "Modelo Educativo Para Niños y Jóvenes en Situación de Calle". Se consideraron las materias de Matemáticas y Español como ejes directivos, después del contacto con los alumnos se vio la necesidad de enriquecer el taller con las unidades de Ciencias Sociales, Ciencias Naturales, Geografía y Cívica y Ética.

La segunda fase estuvo encaminada a integrar una formación productiva (manualidades) con el objetivo de favorecer el autoempleo en los participantes. Para ello se consideraron dos rubros, por un lado el taller lúdico para los alumnos y por otro que los materiales fueran de bajo costo y se puedan reciclar. Los talleres se estructuraron de 11 a 23 sesiones dependiendo de las necesidades de la población, la institución y la disponibilidad de tiempo.

\section{El piloteo}

Para la aplicación del modelo se tuvieron que modificar algunos de los objetivos iniciales, fundamentalmente por problemas de presupuesto; por ejemplo, nunca se llevó a cabo la idea de los autobuses-escuela por el costo que éstos implicaban, tampoco se pudieron concretizar las escuelastaller, estas limitaciones nos llevaron a establecer contacto con las instituciones que se encargan de atender a la población en riesgo de calle.

Se pilotearon los talleres y las unidades pedagógicas en diversas organizaciones gubernamentales así como no gubernamentales del Distrito Federal y en donde se reciben niños y jóvenes en riesgo, de origen urbano o migrante indígenas, así como población en situación calle. En las organizaciones en donde se pudo hacer un trabajo de más larga duración, pues el modelo tuvo una mejor aceptación fueron las siguientes:

El Centro Interdisciplinario para el Desarrollo Social (CIDEs) Centro Colibrí Institución de Asistencia Privada, surgió como una institución de apoyo a niños, adolescentes y familias indígenas que migraron a la Ciudad de México.

La institución cuenta con un centro de día y un programa de intervención directa en los asentamientos donde reside esta población; ofrece servicios educativos, terapéuticos, médicos y de apoyo alimenticio para la población que asiste al centro Colibrí y sus familias.

La población que asiste al centro de día son niños en situación de calle originarios de la comunidad indígena Otomí de Santiago Mexquititlán, Estado de Querétaro. Los padres de la población que asiste al centro se dedica básicamente al comercio informal o a oficios temporales, los niños trabajan en los alrededores de sus hogares en la venta de dulces, mendicidad o la limpia de parabrisas en avenidas. 
El centro de día recibe a niños desde los 6 hasta los 17 años en dos turnos. La institución los organiza en tres grupos para atender sus necesidades educativas según su edad, de esta forma los niños de 6-8 se agrupan en el nivel 1, los de 10-12 en el nivel 2 y el nivel 3 concentra a los niños de entre 13-17.

Para esta institución se incluyó el tema de identidad con su cultura otomí fortaleciendo vínculos afectivos con su comunidad, lo cual también permitía reforzar temas de historia y geografía aunados a las actividades productivas.

El Centro de Día No. 1 del DIF-DF es un centro que brinda atención a niños de entre 5 y 18 años; en su mayoría hijos de comerciantes y trabajadores informales de la zona Centro de la Ciudad de México. Algunos de ellos de procedencia indígena.

La población que atiende usualmente el Centro de Día No. 1 se encuentra dentro de la población en riesgo de calle, ya que los niños mantienen una doble jornada, que implica ir a la escuela así como trabajar con sus padres, ya sea como artesanos o comerciantes. En ocasiones, mientras sus padres venden ellos deambulan por la zona centro. Algunos presentan bajo rendimiento escolar o ausentismo.

La institución tiene un sistema para atender las necesidades educativas brindando un acompañamiento pedagógico en áreas de: preescolar (niños de 5 y 6 años), primaria menor (niños que acuden a 1ro., 2do. o 3er. año de primaria), primaria mayor (niños que acuden a 4to., 5to. y 6to. de primaria) y secundaria (niños que acuden a 1ro., 2do. y 3ro. de secundaria).

La institución Yolia: Niñas de la calle A. C., Centro de Día trabaja fundamentalmente con niñas y jovencitas en riesgo o en situación de calle que tienen entre 6 y 22 años de edad. Cuentan con un centro de día para las niñas en riesgo de calle y un internado para aquellas que quieren dejar la calle. Se trabajó específicamente en el Centro de Día que está ubicado en la colonia Santa María La Ribera.

Los talleres lúdico-productivos que servían de apoyo a las unidades pedagógicas fueron los siguientes:

- Repostería, bombones y chocolates (paletas de bombón, diferentes mezclas con cereales y frutas; trufas, etcétera) $)^{2}$.

- Artesanías (muñecas de trapo, pulseras, piñatas, pintura en papel amate, alhajeros con la técnica de papiroflexia, etcétera).

- Serigrafía (elaboración de grabado, carteles y decoración de playeras).

- Repostería, bombones y chocolates (dulces, postres, paletas y decoración con bombones).

\footnotetext{
${ }^{2}$ Fue tan bien recibido este taller entre la población, que las madres de familia pidieron se les impartiera también a ellas. Atendiendo a esta petición, el trabajo se desarrolló con la consigna de que las madres asistieran junto con algunos de sus hijos, esto se debió a que, en el caso de adultos, no sólo tenía como finalidad el aprendizaje de una actividad generadora de ingresos, sino también fomentar la cercanía y generar dinámicas que fomentaran la socialización entre madre e hijos.
} 
- Dulces tradicionales y gelatinas (paletas de hielo, manzanas acarameladas, dulces de tamarindo, gelatinas con diversos materiales, etcétera).

- Taller de ensaladas y nutrición: preparación de diversas ensaladas analizando las propiedades nutritivas de los alimentos.

\section{Consideraciones derivadas del Piloteo}

A lo largo del pilotaje, se ha observado que la población muestra interés por el aprendizaje de actividades o habilidades que les puedan redituar recursos económicos vía el comercio. Al mismo tiempo, hemos notado una gran apertura en la integración de contenidos pedagógicos y formación técnica; y lo anterior, no sólo ha valido para los niños y jóvenes en situación de calle, sino también para sus familias o incluso para las mismas instituciones en las que hemos aplicado el modelo.

El desarrollo de material didáctico específico a cada tema productivo, el tener la posibilidad de exponer $\mathrm{u}$ ofrecer una degustación de los productos realizados frente a sus pares o sus familias y educadores, así como realizar ejercicios (aún asistidos por el educador) de los distintos momentos de manufactura, en el que los alumnos puedan hacer uso de sus propios saberes y capacidades, ha sido un medio gradual para insertar a los niños y jóvenes en un proceso más amplio de participación y autonomía, así como de responsabilidad.

Pocos sistemas escolarizados funcionan bajo la lógica de adaptarse a la población en situación de calle y, más bien, exigen al sujeto que este se adapte a ellos - aspecto en el que pueden articularse nuevas experiencias de exclusión y fracaso para los niños-, pensamos que hacer un acompañamiento en la transición entre nuestra metodología adaptada y la incursión de los jóvenes en una que estuviera reglamentada desde otros referentes, sería de especial valor.

Tomando en consideración el resultado del piloteo consideramos que las poblaciones que podrían beneficiarse de la aplicación del mismo son las siguientes:

- Niños no escolarizados pero en edad de reincorporarse a la escuela pública.

- Niños escolarizados con necesidad de reforzar sus conocimientos.

- Niños escolarizados con rezago y reprobación parcial en las evaluaciones dentro de sus grupos.

- Niños escolarizados con experiencias de reprobación que no logran pasar de año y se retrasan frente a otros niños de su misma edad.

- Jóvenes que actualmente no asisten a la escuela y, por su edad, ya no están en condiciones de que los acepte la escuela pública; por lo que de continuar su trayectoria académica, deberían recurrir a INEA. 


\section{Los obstáculos para el piloteo}

En este caso nos interesa analizar algunos obstáculos que encontramos en la idea de proponer un modelo de educación para las poblaciones callejeras, más allá de las dificultades debido a la falta de apoyo financiero de la SEP, para aplicar el modelo, más allá del piloteo.

La primera fue la resistencia de algunas organizaciones civiles, salvo en las que pudimos realizar el piloteo, en el sentido de considerar de antemano que los jóvenes no se interesarían en la educación, a pesar de que el modelo propuesto estaba construido recuperando las experiencias de vida de los muchachos y servía como base para ir construyendo aprendizajes significativos. Considero este hecho como una expresión de la actitud paternalista y asistencialista que dominan en la mayor parte de las Asociaciones Civiles y Gubernamentales: habitualmente estas organizaciones tratan de compensar las injusticias que se han cometido con esos jóvenes dándoles ropa, paseos, comida, techo y en algunas ocasiones tratan de facilitarles la asistencia a la escuela regular. Esta posición dificulta mucho el solicitarles algo a cambio de que promueva la responsabilidad y su lugar como sujeto en la sociedad. Llegamos incluso a ser testigos de una organización que impidió que los jóvenes se apropiaran completamente de un proyecto productivo, sin pensar que eso les habría ayudado a ser realmente autónomos y que la Asociación podría iniciar otro. Algunas de estas organizaciones excepcionalmente promueven la ciudadanía y los derechos de los jóvenes.

El segundo obstáculo proviene de lo que yo llamo el mercado de lo humanitario (Taracena, 2010) en donde el hecho de promover las becas o ayudas para este tipo de población, con el fin de obtener más donativos, se realiza desde imágenes estigmatizadas de los niños y niñas; y de sus condiciones. Cuando aceptan sujetarse a las reglas de este mercado humanitario, terminan construyendo su identidad a través de esta imagen social devaluada.

El tercer obstáculo tiene que ver con la reticencia de muchas organizaciones de trabajar con aproximaciones biográficas, la respuesta que obtuvimos a menudo es que no debíamos evocar la historia del niño o de la niña, si no eso alteraba la estabilidad que hubiese ya adquirido. Tengo la convicción que para poder acompañar a un joven que ha tenido una experiencia de abandono y que ha sobrevivido en las calles, es necesario recuperar su historia, ya que de ella puede aprender como buscar alternativas diferentes al rechazo a la sociedad o a la lógica del aquí y el ahora que le impide la construcción de un proyecto a futuro. Sartre (1979) plantea que no podemos cambiar nuestra historia pero si nuestra relación con ella. De acuerdo con el autor el sujeto se historializa, es decir opera un cambio en su relación con el mundo para constituirse en un sí mismo. Así pensamos que la única manera de salir de la alienación es reconstruyendo y reinventando su historia.

El cuarto obstáculo proviene de las condiciones propias de los jóvenes y de la incapacidad del Estado de proponer soluciones a sus problemas. En primer lugar el no tener un lugar fijo donde pernoctar y poder asearse y comer correctamente, en segundo lugar la falta de papeles que los puedan acreditar como ciudadanos de nuestro país, tercero la necesidad de subsistir día a día, y finalmente las adicciones frente a las cuales, a menudo no existen alternativas de tratamiento. Todo esto propi- 
cia que los jóvenes callejeros no puedan hacer proyectos a mediano y largo plazo. La cultura de la calle se desarrolla en este contexto y propicia el vivir en el aquí y el ahora, sin planes de mañana.

\section{Conclusiones}

En la época actual se requiere un esfuerzo para pensar la educación de manera alternativa a la de la escuela tradicional, de manera que pueda responder a grupos con modos de socialización diferentes. Se necesita acercar la escuela a los niños y crear programas que se ajusten a sus recursos y respondan a sus condiciones de vida.

Pensar en una propuesta educativa de estas características, nos implica pues, crear rutas de contacto con él, para trabajar no sólo la escisión jugada en la historia que ha vivido y sus imbricaciones con prácticas de riesgo como la drogadicción, el alcoholismo, el riesgo a contraer infecciones de transmisión sexual, los embarazos no planeados, la separación o fractura de los vínculos familiares, la violencia, la inequidad, etcétera; apuntando a una reelaboración al menos simbólica o imaginaria de ese pasado que le permita proyectarse a futuro y recobrar así la capacidad de historicidad del niño y del joven, así como su ciudadanía y el ejercicio de sus derechos. En esa medida, los educadores de calle se convierten en los primeros interlocutores de un cierto deseo social, porque los jóvenes en situación de calle se reinserten a sistemas de vida más estructurados.

Adicionalmente, también implica generar los medios para favorecer y subrayar el arraigo con la vida en sociedad; en primer instancia, generando los vínculos con instituciones especializadas en trabajar contra esa alienación que el uso de drogas genera en estos niños y jóvenes y, de manera paralela, acercando la escuela a las condiciones reales de vida del niño y el joven en situación de calle mediante la puesta en marcha de un programa flexible de nivelación educativa — por lo menos a nivel básico-, que promueva otros elementos de innovación como el acercamiento al mundo de lo estético, el arte o la creatividad, la capacitación para la generación de actividades remuneradas, la formación educativa desde sistemas de tecnología multimedia, la creatividad, la renovación de la vivencia de los espacios de ocio y esparcimiento, la planeación de prácticas que se orienten al cuidado de la salud y, finalmente, la visibilidad de otras posibilidades de adscripción a la sociedad.

Sin embargo el análisis de los obstáculos, nos lleva a pensar que existen dispositivos simbólicos que están encaminados al olvido, a negar historias, a mantener la dependencia y la marginalidad, a propiciar imágenes estigmatizadas, en los cuales las asociaciones civiles participan sin tener conciencia plena de la perpetuación del no lugar en el que se pone a esos jóvenes.

Pensar en los o las jóvenes en situación de calle como sujetos educativos requiere no solamente la planeación de contenidos y de un modelo pedagógico, sino de un cambio profundo en el funcionamiento de las organizaciones y de la mirada social que se tiene de estas poblaciones. 
Mientras los jóvenes que sobreviven en las calles no puedan negociar un lugar social difícilmente podrán situarse como sujetos de deseo, las intervenciones educativas tendrán entonces como función acercarlos a las instituciones y hacerlos conscientes de apropiarse de su ciudadanía.

\section{Bibliografía}

Albarrán, G. \& Taracena, E. (2012). Análisis de implicación de educadores de niños y niñas en riesgo de calle: el trabajo en una organización de asistencia social en la Ciudad de México. Revista Latinoamericana de Ciencias Sociales, 10(2), pp. 957-970.

Camilleri, C.; Kastersztein, J.; Lipiansky, E. M.; Malewska-Peyre, H.; Tabeada-Leonetti, I. \& Vázquez, A. (1990). Stratégies identitaires. Paris: Presses Universitaires de France.

Flores, E. (2010). Género, corporalidad y uso de drogas. Estudio cualitativo con un grupo de jóvenes en situación de calle. México: Becas Posdoctorales FES-I, UnAM.

Goffman, E. (1973). La mise en scène de la vie quotidienne. Paris: Editions. Minuit.

Halbwachs, M. (2001). Les cadres sociaux de la mémoire. Paris: Albin Michel.

Lipiansky, E. M. (1992). Identité et communication. L'expérience groupale. Paris: Presses Universitaires de France.

Rosset, C. (1999). Loin de moi. Étude sur l'identité. Paris: Editions de Minuit.

Sartre, P. (1979). L'être et le néant. Essai d'ontologie phénoménologique. Paris: Edition Gallimard.

Taracena, E. y M. L. Tavera (2000). "La función del grupo en los niños de la calle en la ciudad de México". En: Laje, M. y J. Rearte. Libro de ponencias: Investigación social sobre la Infancia y Adolescencia. Córdoba: UNICEF-Universidad de Córdoba-Universidad de Buenos Aires.

—— y G. Albarrán (2010). Modelo Educativo para niños y jóvenes en situación de calle. México: SEP-FEs Iztacala.

— y E. Flores (2012). Educación para poblaciones callejeras. Reflexiones sobre un modelo educativo y el perfil de los educadores de calle. México: Versión digital. SEP-UNAM.

_ (2013). Un enfoque socioclínico del fenómeno de la vida en la calle. México: Juan Pablos Editores.

Tajfel, H. (ed.) (1972). Introduction a la psychologie sociale. Tome 1. Paris: Larousse

Todorov, T. (2000). Los abusos de la memoria. Barcelona: Paidós.

Winnicott, D. W. (2005). Deprivación y Delincuencia. Argentina: Paidós.

Recibido: 11/10/13

Dictaminado: 29/12/13

Corregido: 05/02/14

Aceptado: 21/02/14 